The Egyptian Journal of Hospital Medicine (July 2019) Vol. 76 (5), Page 4062-4067

\title{
Frequency and Predictors of Extra-articular Manifestations in Patients with Rheumatoid Arthritis
}

\author{
Dalia A. EISherbiny \\ Internal Medicine Department, Rheumatology Division, Faculty of Medicine, Ain Shams University, Cairo, Egypt \\ Corresponding author: Dalia AbdelHamid ElSherbiny - Mobile: +20 1227437707, \\ E-mail: dalia_elsherbiny@hotmail.com
}

\section{ABSTRACT}

Aim: To evaluate the frequency and the predictors of extra-articular manifestations (EAMs) in rheumatoid arthritis (RA) patients.

Patients and Methods: This study included 100 adult rheumatoid arthritis patients. A full medical history and a thorough clinical and rheumatological examinations, along with laboratory and radiological investigations were done. RA disease activity using the modified disease activity score (DAS28), validated Arabic version of the health assessment questionnaire (HAQ-A) and the simplified erosion narrowing score (SENS) were calculated. Results: EAMs were detected in 73 patients $(73 \%)$ of the RA patients; the most common EAMs were subcutaneous rheumatoid nodules (45\%), followed by anemia (43\%), ocular affection (23\%), pulmonary affection (interstitial lung disease ILD) (15\%), neuropathy (10\%) while renal and cardiac involvements were $(2 \%)$ and $(1 \%)$ respectively. There were statistically significant higher levels of age, disease duration, disease activity (DAS28), severe functional disability (HAQ-A), joint damage (SENS), rheumatoid factor (RF) positivity and CRP levels among RA patients with EAMs than those without EAMs. The multivariate regression analysis of the possible predictors of RA EAMs showed that disease duration (OR 1.8, 95\% CI. 1.2-2.9, $\mathrm{p}=0.006)$ and disease activity DAS28 (OR 1.6, 95\% CI 1.0-2.4, p=0.045) independently affect the occurrence of EAMs in RA patients.

Conclusion: Extra-articular manifestations are common among rheumatoid arthritis patients. Disease duration and disease activity were independent predictors of extra-articular manifestations occurrence in rheumatoid arthritis.

Keywords: Extra-articular manifestations; Rheumatoid arthritis; Disease activity score(DAS28); Frequency; Predictors.

\section{INTRODUCTION}

Rheumatoid arthritis (RA) is the most common inflammatory joint disease, affecting $1-2 \%$ of the population worldwide ${ }^{[1]}$. RA is a chronic systemic inflammatory disease that can involve other tissues and organs as well as synovial joints. Extra-articular manifestations (EAMs) are all the conditions and symptoms which are not directly related to the locomotor system ${ }^{[2]}$. Most organs can be involved ${ }^{[3]}$. Extra-articular manifestations of RA occur in about $40 \%$ of patients, either in the beginning or during the course of their disease [4]. Epidemiological studies of extra-articular RA manifestations have emphasized their major role as predictors of premature mortality in patients with RA ${ }^{[5]}$. Extra-articular RA is a serious condition, and RA patients with EAMs should be aggressively treated and monitored [6].

Aim of this study is to detect the frequency and the predictors of EAMs in rheumatoid arthritis; and to evaluate its relationship with the disease activity and other RA disease measuring parameters

\section{SUBJECTS AND METHODS}

This study was an observational cross-sectional study that included one hundred RA patients who fulfilled the American Colleague of Rheumatology / European League against Rheumatism (ACR/EULAR) 2010 classification criteria ${ }^{[7]}$. They were selected from Rheumatology Outpatient Clinic and Internal Medicine Department of Ain Shams University Hospital.

\section{Ethical considerations:}

The World Health Organization (WHO) and the Declaration of Helsinki recommendations were followed, in terms of protecting the rights and well-being of the studied people ${ }^{[8]}$. The nature of the present study was explained to all participants. The laboratory and radiological procedures represent standard care pose no ethical conflicts. Informed written consent was obtained from all participants. At the end of the study, all patients were informed about the results of the study and received appropriate recommendations and treatment. The study was approved by the local ethical committee at the Faculty of Medicine, Ain Shams University.

\section{All patients were subjected to the following:}

- Detailed medical history taking and full clinical examination with special emphasis on musculoskeletal and extra-articular manifestations including pulmonary manifestations. Assessment of RA disease activity state was done by using disease activity score (DAS28). A score $\leq 2.4$ was considered to be in disease remission, mild RA disease activity $\leq 3.6$, moderate $>3.6 \leq 5.5$, and high disease activity $>5.5{ }^{[9]}$. Functional disability was evaluated using a validated Arabic version of the health assessment questionnaire (HAQ-A) completed by each patient ${ }^{[10]}$.

- Routine laboratory and serological investigations were performed including: complete blood count (CBC): using coulter JS + cell counter, erythrocyte sedimentation rate 
ejhm.journals.ekb.eg

(ESR) by modified Westergren method, CRP titer (mg/dl) using latex agglutination test, liver and renal function tests. Rheumatoid factor titer (RF) by using latex agglutination test.

- Plain X-ray posterior-anterior (PA) view of both hands, was done for assessment of radiological joint damage using the simple narrowing erosion score (SENS) ${ }^{[11]}$.

- Slit lamp ophthalmoscopy examination.

- Plain chest X-ray posterior-anterior (PA) view.

- High resolution computed tomography scan (HRCT) chest was done for patients with symptoms, signs and of plain chest X-ray findings suggestive of pulmonary affection.

- ECG.

-Transthoracic echocardiography was done on clinical judgement for symptomatic patients.

\section{Statistical Analysis}

Data entry, processing and statistical analysis was carried out using MedCalc ver. 18.2. (MedCalc, Ostend, Belgium). Tests of significance (Mann-Whitney U test, Chi square tests and multivariate regression analysis) were used. Data was presented and suitable analysis was done according to the type of data (parametric and nonparametric) obtained for each variable. P-values less than $0.05(5 \%)$ was considered to be statistically significant.

\section{RESULTS}

In this study, a total of 100 adult RA patients. Their age at disease onset was mean (SD) of 34.69 (11.4) years, with mean (SD) of disease duration of 79.2 (58.8) months. The sociodemographic characteristics of the studied patients are shown in Table 1.

Table 1: Sociodemographic characteristics of the studied rheumatoid arthritis (RA) patients

\begin{tabular}{ll}
\hline Parameter & No. Of patients (\%) \\
\hline Age Mean $(\boldsymbol{S D})$ & $43.3(11.9)$ \\
\hline Sex: & $21(21.0)$ \\
- Male & $79(79.0)$ \\
- Female & \\
\hline Marital Status: & $11(11.0)$ \\
- Single & $85(85.0)$ \\
- Married & $4(4.0)$ \\
- Widow & \\
\hline Residence: & $75(75.0)$ \\
- Cairo & $25(25.0)$ \\
- Outside & \\
\hline Occupation: & $12(12 \%)$ \\
- Working & $15(15 \%)$ \\
- Unemployed & $3(3.0 \%)$ \\
- Retired & $70(70 \%)$ \\
- Housewife & $17(17.0)$ \\
\hline Smoking & $3(3.0)$ \\
\hline Joint Surgery &
\end{tabular}

Most of the studied RA patients (60\%) were treated by disease modifying anti-rheumatic drugs (DMARDs), oral steroids $(5-7 \mathrm{mg} /$ day) and non-steroidal anti-inflammatory drugs (NSAIDs) combination. Methotrexate was the most frequent drug of choice of the DMARDs used for treatment of RA in our studied patients $(70 \%)$. Chronic coexisting diseases were reported in 20 patients $(20 \%)$, while RA was the only pathology in $80(80 \%)$. The associated comorbidities were hypertension (12\%), diabetes mellitus $(5 \%)$ and one patient $(1 \%)$ with chronic liver disease.

Routine laboratory data and full clinical assessment were done for all the RA studied patients and results were shown in Table 2. Among the RA patients $(60 \%)$ of the them had high disease activity (DAS28 > 5.5) mainly erosive $(86 \%)$, seropositive $(71 \%$ were positive rheumatoid factor (RF), with $(46 \%)$ had severe functional disability (HAQ-A>2-3) and (25\%) with typical joint deformities.

Table 2: Laboratory and Clinical data of the rheumatoid arthritis patients

\begin{tabular}{ll}
\hline Variable & Mean (SD) \\
\hline Hb (gm/dl) & $12(1.83)$ \\
\hline WBC (103/ml) & $6.6(1.5)$ \\
\hline Platelet count (103/ml) & $292(113.4)$ \\
\hline AST (IU/L) & $16.5(8.6)$ \\
\hline ALT (IU/L) & $15.3(9)$ \\
\hline Creatinine (mg/dl) & $0.9(0.28)$ \\
\hline ESR (mm/hr) & $45.9(28.8)$ \\
\hline CRP (mg/dl) & $3.8(4.1)$ \\
\hline 24hours urinary protein & $3.5(0.87)$ \\
(mg/24h) & \\
\hline Tender joints No. (\%) & $12(8.9)$ \\
\hline Swollen joints No. (\%) & $8(8.2)$ \\
\hline Morning Stiffness (minutes) & $235.8(453)$ \\
\hline DAS 28 & $6.0(1.65)$ \\
\hline HAQ-A & $1.9(0.9)$ \\
\hline SENS & $28.3(22.6)$ \\
\hline
\end{tabular}

Hb, hemoglobin; WBC, white cell count; ESR, erythrocyte sedimentation rate; CRP, C-reactive protein; VAS, visual analogue scale; DAS, disease activity score; HAQ-A, Arabic version of the health assessment questionnaire; SENS, simple erosion narrowing score;

EAMs were detected in 73 of our RA patients (73\%) at any time during disease history; the most common EAMs were subcutaneous rheumatoid nodules (45\%), followed by anemia (normochromic-normocytic anemia) (43\%), ocular affection (23\%), pulmonary affection (interstitial lung disease ILD) (15\%), neuropathy (10\%), renal (secondary amyloidosis confirmed by renal biopsy) and cardiac affection (2\%) and (1\%) respectively as shown in Table 3. 
ejhm.journals.ekb.eg

Table 3: Extra-articular manifestations (EAMs) among the studied rheumatoid arthritis patients

\begin{tabular}{clc}
\hline & EAM & $\begin{array}{c}\text { Number of } \\
\text { patients (\%) }\end{array}$ \\
\hline Dermatological & - SRN & $45(45.0)$ \\
& - Vasculitis & $1(1.0)$ \\
\hline & Pulmonary (ILD) & $15(15.0)$ \\
\hline Hematological & - Anemia & $43(43.0)$ \\
& - Lymphoma & $1(1.0)$ \\
\hline Ocular: & - Episcleritis & $5(5.0)$ \\
& - Scleritis & $1(1.0)$ \\
& -Keratoconjunctivitis Sicca & $17(15.0)$ \\
\hline & Neuropathy (SPN) & $10(10.0)$ \\
\hline Renal & (secondary amyloidosis) & $2(2.0)$ \\
\hline Cardiac & affection:(pericarditis) & $1(1.0)$ \\
\hline
\end{tabular}

SRN, subcutaneous rheumatoid nodules; ILD, interstitial lung disease; SPN, Sensory peripheral neuropathy.

Correlation studies regarding EAMs occurrence in RA Table 4, revealed the following:

There were statistically significant higher levels of age, disease duration, disease activity (DAS28) (Figure 1), severe functional disability (HAQ-A), joint damage (SENS), rheumatoid factor (RF) positivity and CRP level among the RA patients with EAMs than those without EAMs.

Table 4: Comparison between the rheumatoid arthritis (RA) patients with extra-articular manifestations (EAMs) and the rheumatoid arthritis patients without EAMs

\begin{tabular}{lccc}
\hline Parameter & $\begin{array}{c}\text { RA patients with } \\
\text { EAMs }\end{array}$ & $\begin{array}{c}\text { RA patients without } \\
\text { EAMs }\end{array}$ & P value \\
\hline No. of patients (\%) & $73(73.0)$ & $27(27.0)$ & \\
\hline Age Median (IQR) & $45(36-52.2)$ & $30(25-43.7)$ & $\mathbf{0 . 0 0 0 9 6 8}$ \\
\hline Age of onset Median (IQR) & $35(27-38)$ & $32(26-41)$ & 0.083 \\
\hline $\begin{array}{l}\text { Sex: N (\%) } \\
\text { - Male }\end{array}$ & $17(23.3)$ & $4(14.8)$ & 0.3581 \\
- Female & $56(76.7)$ & $23(85.2)$ & \\
\hline $\begin{array}{l}\text { Disease duration Median } \\
\text { (IQR) }\end{array}$ & $6(4-10)$ & $3(2.6-3)$ & $<\mathbf{0 . 0 0 1}$ \\
\hline DAS28 Median (IQR) & $6.6(5.1-7.6)$ & $5.4(4.1-5.9)$ & $\mathbf{0 . 0 0 0 3 2}$ \\
\hline HAQ Median (IQR) & $2.2(1.5-3)$ & $1.6(0.3-2)$ & $\mathbf{0 . 0 0 1 0 9 8}$ \\
\hline SENS Median (IQR) & $35(14-57)$ & $10(1.5-14.2)$ & $\mathbf{0 . 0 0 0 0 0 5}$ \\
\hline $\begin{array}{l}\text { Rheumatoid factor (RF): No. } \\
\text { (\%) }\end{array}$ & & & \\
- Negative & $14(19.2)$ & $15(55.6)$ & $\mathbf{0 . 0 0 0 4}$ \\
- Positive & $59(80.8)$ & $12(44.4)$ & \\
\hline CRP Median (IQR) & $3(1.1-6.9)$ & $1.2(0.6-2.8)$ & $\mathbf{0 . 0 2 3 1}$ \\
\hline $\begin{array}{l}\text { Smoking: No. }(\%) \\
\text { - Non-Smoker }\end{array}$ & $58(79.5)$ & $25(92.6)$ & 0.1223 \\
- Smoker & $15(20.5)$ & $2(7.4)$ & \\
\hline
\end{tabular}

IQR: interquartile ratio. Mann-Whitney U test used. \% per column total. No, number; SD, standard deviation; DAS, disease activity score; HAQ-A, Arabic version of the health assessment questionnaire; SENS, simple erosion narrowing score; Bold values are significant at $\mathrm{p}<0.05$.

The multivariate regression analysis of the possible predictors of RA EAMs showed that disease duration and disease activity DAS28 independently affect the occurrence of EAMs in RA patients Table 5.

Table 5: Predictors of extra-articular manifestations (EAMs) in the rheumatoid arthritis patients by using the multivariate regression analysis

\begin{tabular}{lccc}
\hline Parameter & $\begin{array}{c}\text { Regression } \\
\text { Coefficient }\end{array}$ & P value & OR (95\% CI) \\
\hline Disease Duration & 0.615 & $\mathbf{0 . 0 0 6}$ & $1.8(1.2-2.9)$ \\
\hline SENS & 0.032 & 0.117 & $1.03(0.99-1.1)$ \\
\hline DAS28 & 0.442 & $\mathbf{0 . 0 4 5}$ & $1.6(1.0-2.4)$
\end{tabular}

SENS, Simple Erosion Narrowing Score; DAS28, modified Disease Activity Score; OR, Odds Ratio; CI, Confidence Interval; Bold values are significant at $\mathrm{p}<0.05$. 


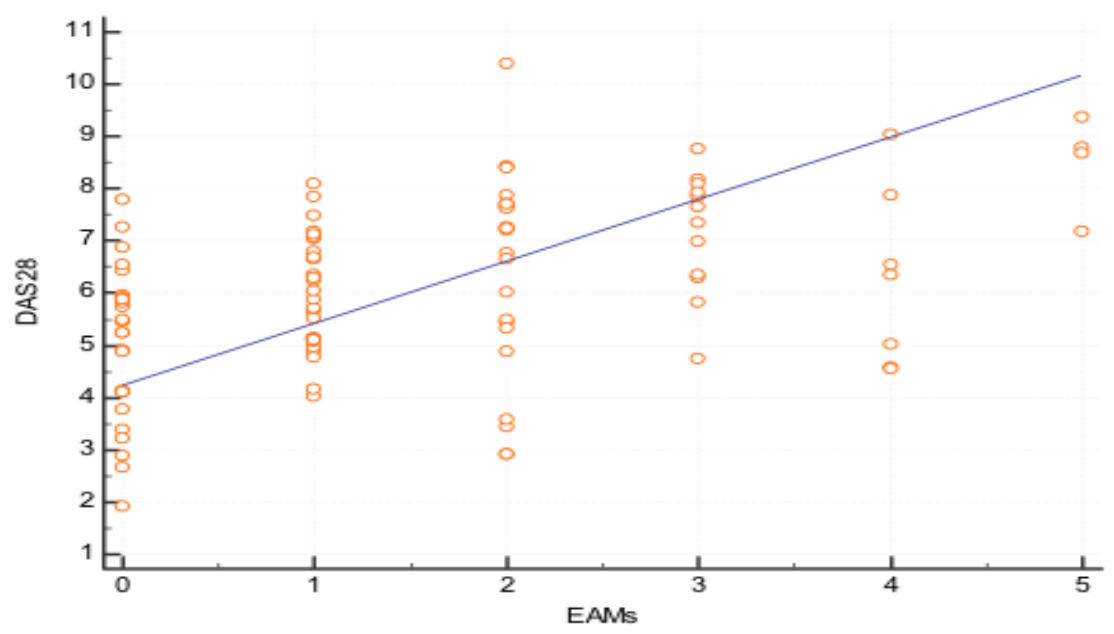

Figure 1: Correlation between the occurrence of extra-articular manifestations (EAMs) and the rheumatoid arthritis disease activity score (DAS28).

\section{DISCUSSION}

This study was conducted on 100 consecutive adult patients with definite RA. The mean age of all RA patients was $(41.3 \pm 11.9)$ years with a mean $(\mathrm{SD})$ disease duration of 79.2(58.8) months. Seventy-nine (79\%) were females and $21(21 \%)$ were males, $(75 \%)$ lived in urban areas, $(85 \%)$ were married and $(70 \%)$ were housewives; this came in agreement with Ho et al. ${ }^{[12]}$.

As regards medication used, (60\%) were on combination therapy of DMARDs, steroids and NSAIDs. Methotrexate was the most frequent choice of DMARDs among our patients. none of the RA patients were prescribed biological therapy. This came in partial agreement with Nicassio et al. who reported that participants reported a combination of biologic DMARDs, synthetic DMARDs, NSAIDs/analgesics, and other medications (e.g. psychotropics) used to manage their RA and comorbid medical/psychiatric problems ${ }^{[13]}$.

Regarding RA disease activity measures, the mean disease activity DAS28 score was $(6 \pm 1.6)$, the mean typical articular damage SENS was $(28.3 \pm 22.6)$ and the mean functional disability HAQ-A score was $(1.9 \pm 0.9)$ which came in agreement with van den Hoek et al. ${ }^{[14]}$.

The frequency of EAMs was (73\%) among the RA studied patients. This is higher than in North American populations (40\%) ${ }^{[15]}$, Spanish patients $(36 \%)^{[16]}$ and Italian patients $(41 \%)^{[17]}$, but close to Saudi patients ${ }^{[18]}$ and much lower than another Egyptian study done in 2014, which found that $100 \%$ of their 50 patients had EAMs ${ }^{[19]}$.
There are different data on the incidence of EMAs in RA, few large studies were published on incidence and prevalence trends of EAMs over time. Despite this, there is a widespread belief that severe EAMs are becoming less common. This study does not support such a concept, which is in concordance with Turesson and colleagues [20]; who did not find any major decrease in the incidence of EAMs in RA.

In this study, EAMs were reported mainly in older females with longer disease duration, severe disease activity, more functional disability, positive rheumatoid factor (RF), high CRP level and more radiological damage. These findings were similar to previous reports addressed by Sayah and English ${ }^{[21]}$.

Subcutaneous nodules (SCN) were the most common EAMs in the studied RA patients (45\%), while anemia (normochromic normocytic) occurred in (43\%), followed by ocular affection (23\%), Interstitial lung disease (ILD) in (15\%), peripheral neuropathy in (10\%), renal affection (secondary amyloidosis) (2\%) with only (1\%) presence of cutaneous vasculitis and cardiac affection; which came in agreement with Vela et al. ${ }^{[22]}$.

Results obtained warrant the conclusion that SCN incidence in RA patients is in agreement with the fact that classic rheumatoid nodules are the most common extraarticular feature of RA ${ }^{[21]}$. They occur mainly in rheumatoid factor positive RA patients and in early RA give risk to severe extra-articular manifestations. Moreover, the apparently increased incidence of EAMs as a whole was mainly due to an increased number of patients with rheumatoid nodules in later decades ${ }^{[20]}$. 
Comparing our results to other reports, rheumatoid nodules, which are reported to occur in $45 \%$ of the RA patients, were only found in (3\%) of Saudi patients ${ }^{[18]}$ and $(8 \%)$ in another study conducted among Egyptians ${ }^{[19]}$.

This may be contributed to the increased number of rheumatoid factor positive patients $(71 \%)$, excess usage of methotrexate (70\%), lack of treatment by new biological agents and/or due to genetic variation.

Genetics seems to play a role in the appearance of rheumatoid nodules. It has been shown that the HLA-DR4 haplotype (including the heterogenous group of DRB1 alleles) is predictive of the risk of subcutaneous nodules in RA. In a study of 29 Egyptian RA patients HLADRB1 $\mathrm{SE}+$ alleles were highly expressed in this group ${ }^{[23]}$.

Multiple regression analysis of the possible predictors of EAMs among RA patients showed that only disease duration (OR 1.8, 95\% CI, $\mathrm{p}=0.006$ ) and disease activity (DAS28) (OR 1.6, 95\% CI, p=0.045) were significant predictors of EAMs occurrence.

These findings were different with the study done by Turesson and coworkers who found that previous smoking, early disability, age and RF were significant predictors of EAMs overall ${ }^{[20]}$. But other studies reported that high disease activity, disability, smoking and RF can predict the development of severe EAMs in RA ${ }^{[24]}$.

Data are conflicting as to whether the occurrence of EAMs decreases with prolonged disease duration. Turesson et al. demonstrated that EAMs does not decrease during a 10 year follow up ${ }^{[25]}$. This study showed a similar finding, as the studied RA patients reported more EAMs with prolonged disease duration. Although smoking was suggested as a risk factor for EAMs development, we could not relate a significant association in this study as only $17 \%$ of the RA patients were active smokers.

In conclusion, diagnosis of extra-articular rheumatoid arthritis is a challenge for clinicians, given its variable and complex presentation, and the lack of specific diagnostic tests; it must be based on clinical recognition and exclusion of other causes of the signs and symptoms. This study showed that extra-articular manifestations are common among rheumatoid arthritis patients. Disease duration and disease activity were independent predictors of extra-articular manifestations occurrence in rheumatoid arthritis. Extra-articular rheumatoid arthritis is a serious condition, and rheumatoid patients with extra-articular manifestations should be recognized early and managed promptly to prevent disease morbidity and mortality, and to assure to patients a better quality of life.

\section{REFERENCES}

1. Turesson C, Matterson EL (2004): Management of extra-articular disease manifestations in rheumatoid arthritis. Curr Opin Rheumatol.,16(3):206-211.

2. Mielants H, Van den Bosch F (2009): Extra-articular manifestations. Clin Exp Rheumatology, 27(55): S56S61.

3. Al-Ghamdi A, Attar SM (2009): Extra-articular manifestations of rheumatoid arthritis. Annals of Saudi Medicine, 29:189-193.

4. Cimmino MA, Salvarani C, Macchioni P (2000): Extraarticular manifestations in 587 Italian patients with rheumatoid arthritis. Rheumatol Int.,19(6):213-217.

5. Bongartz T, Cantaert T, Atkins SR et al. (2007): Cirullination in extra-articular manifestations of rheumatoid arthritis. Rheumatol (Oxford), 46(1):70-75.

6. Young A, Koduri G (2007): Extra-articular manifestations and complications of rheumatoid arthritis. Best Pract Res Clin Rheumatol., 21(5):907-927.

7. Aletaha D1, Neogi T, Silman AJ, Funovits J, Felson DT, Bingham CO et al. (2010): Rheumatoid arthritis classification criteria: an American College of Rheumatology/European League Against Rheumatism collaborative initiative. 3rd Arthritis Rheum., 62(9):25692581.

8. Goodyear MD, Eckenwiler LA and Ellis C (2008): Fresh thinking about the Declaration of Helsinki, BMJ., 337: a2128.

9. Aletaha D, Ward MM, Machold KP, Nell VP, Stamm T, Smolen JS (2005): Remission and active disease in rheumatoid arthritis: defining criteria for disease activity states. Arthritis Rheum. ,52(9):26252636.

10. El Meidany YM, El Gaafary MM, Ahmed I (2003): Cross-cultural adaptation and validation of an Arabic Health Assessment Questionnaire for use in rheumatoid arthritis patients. Joint Bone Spine, 70(3):195-202.

11. Dias EM, Lukas C, Landewé R, Fatenejad S, van der Heijde D (2008): Reliability and sensitivity to change of the Simple Erosion Narrowing Score compared with the Sharp-van der Heijde method for scoring radiographs in rheumatoid Arthritis. Ann Rheum Dis., 67(3):375-379.

12. Ho RC, Fu EH, Chua AN, Cheak AA, Mak A (2011): Clinical and Psychosocial Factors Associated with Depression and Anxiety in Singaporean Patients with Rheumatoid Arthritis: Depression and Anxiety in Singaporean Rheumatoid Arthritis. International Journal of Rheumatic Diseases, 14 (1): 37-47.

13. Nicassio PM, Ormseth SR, Kay M, Custodio M, Irwin MR, Olmstead $\mathrm{R}$ et al. (2012): The Contribution of Pain and Depression to Self-Reported Sleep Disturbance in Patients with Rheumatoid Arthritis. Pain, 153 (1): 107-12. 
14. van den Hoek J, Roorda LD, Boshuizen HC, van Hees J, Rupp I, Tijhuis GJ et al. (2013): Long-Term Physical Functioning and Its Association with Somatic Comorbidity and Comorbid Depression in Patients with Established Rheumatoid Arthritis: A Longitudinal Study: Comorbidity and Long-Term Physical Functioning in RA. Arthritis Care \& Research, 65 (7): 1157-65.

15. Hochberg MC, Johnston SS, John AK et al. (2008): The incidence and prevalence of extra-articular and systemic manifestations in a cohort of newly diagnosed patients with rheumatoid arthritis between 1999 and 2006. Curr Med Res Opin., 24(2): 469-480.

16. Carmona L, González-Álvaro I, Balsa A et al. (2003): Rheumatoid arthritis in Spain: occurrence of extra-articular manifestations and estimates of disease severity. Ann Rheum Dis., 62:897-900.

17. Cimmino MA, Salvrani C, Macchioni P (2000): extra articular manifestation in 587 Italian patients with rheumatoid arthritis. Rheumatol Int., 19(6): 213217.

18. Al-Ghamdi A, Attar SM (2009): Extra-articular manifestations of rheumatoid arthritis: a hospitalbased study. Ann Saudi Med., 29(3):189-193.

19. El-Baz WF, Mousa SG, Tawfeek NA, Shawky AM, Ahmed MM, Mohamed RA (2014): Extra Articular Manifestations in Egyptian Rheumatoid Arthritis Patients. Egypt $\mathrm{J}$ Rheumatology and Clinical Immunolog., 2 (1):71-79.
20. Turesson C, O'Fallon WM, Crowson CS, Gabriel SE, Matteson EL (2003): Extra-articular disease manifestations in rheumatoid arthritis: incidence trends and risk factors over 46 years. Ann Rheum Dis., 62(8):722-727.

21. Sayah A, English III JC (2005): Rheumatoid arthritis: A review of the cutaneous manifestations. J Am Acad Dermatol., 53(2):191-209.

22. Vela $P$ (2014): Extra-articular manifestations of Rheumatoid Arthritis, Now. EMJ Rheumatol., 1:103112.

23. Farouk HM, Mansour HE, Rahman SA, Mostafa AA, Shamy HA, Zarouk WA (2009): Effect of the human leukocyte antigen HLA-DRB1 and anti-cyclic citrullinated peptide on the outcome of rheumatoid arthritis patients. Braz J Med Biol Res., 4(9): 831-838.

24. Nyhäll-Wåhlin BM, Petersson IF, Nilsson JA, Jacobsson LT, Turesson C (2009): the BARFOT study group, High disease activity disability burden and smoking predict severe extra-articular manifestations in early rheumatoid arthritis, Rheumatology,48(4): 416-420.

25. Turesson C, McClelland RL, Christianson TJ, Matteson EL (2004): No decrease over time in the incidence of vasculitis or other extraarticular manifestations in rheumatoid arthritis: Results from a community- based study. Arthritis \& Rheumatism, 50: 3729-3731. 